now reflected in an avalanche of publications in the primary literature.

When new material is appearing at such an alarming rate, to embark on a book can be a dangerous decision. Exceptions are books that aim to impose some sort of order on the apparent chaos of the primary literature and those that advance a novel framework within which the new discoveries can be set. Tony Campbell's Intracellular Calcium falls squarely into the first category.

After discussing the "Natural History of Calcium" and "Calcium Methodology", Campbell sets out to draw together the arguments for and against a role for $\mathrm{Ca}$ in a host of cellular processes with chapters on "Intracellular $\mathrm{Ca}$ and the Electrical Activity of Cells", "Calcium and Cell Movement", "Intracellular $\mathrm{Ca}$ and Intermediary Metabolism", "Endocytosis and Exocytosis", "The Reproduction and Development of Cells" and "The Pathology and Pharmacology of Intracellular Ca". Each of these often contains long accounts of basic cell biology as an essential introduction to discussion of the possible roles of calcium. Unfortunately, except where that role is already well known, these chapters often end rather inconclusively. They nevertheless certainly highlight many unsolved problems of cell biology in which calcium may well be involved.

Such a wide sweep has, however, posed obvious difficulties for the author and despite 556 pages the book falls somewhere between being a natural history of intracellular calcium and a critical discussion of those processes where involvement of calcium is still controversial. In consequence some important growth areas of real significance to "control by calcium" are under-represented and presented in a relatively uncritical fashion. Two obvious examples are phosphoinositol metabolism and the transport of calcium across membranes; but I suspect that most specialists will find fault with the presentation of their own particular neck of the calcium wood. It is a pity that the author did not seek more feedback before publication. In this way the most glaring errors might have been avoided and the author might also have been encouraged to reference all the most important observations with original papers. As it is, the policy is mixed: sometimes original papers are quoted, in other places reviews, but all too often interesting observations go incognito.

It is all too easy to find fault. This is a very personal account of the many roles of intracellular calcium that will be an obvious starting point for those entering the field. It will also, I feel sure, infect both the old hand and the new with some of Tony Campbell's great enthusiasm for his subject.

P.F. Baker is Halliburton Professor of Physiology at King's College, University of London.

\section{Look back to viral oncology}

\section{Robin Weiss}

Oncogenic Viruses, 3rd Edn.

By Ludwik Gross.

Pergamon: 1983. Two volumes, pp. 1,203. $£ 100, \$ 200$.

LuDWIK Gross has influenced the development of experimental oncology in the postWar period through three distinct contributions. First, after many years of frustrating experimental work, in 1951 he showed that the thymic lymphoma of AKR mice could be transmitted to new-born $\mathrm{C} 3 \mathrm{H}$ mice by cell-free filtrates; this discovery of murine leukaemia virus, following Bittner's demonstration of the milk factor causing mammary carcinoma in mice 15 years earlier, firmly established that viruses cause cancer in mice, and led to a resurgence of tumour virus research. Second, in 1953, Gross reported that salivary gland tumours (also induced by the thymoma extracts) were caused by a distinct agent, later named polyoma virus by Sarah Stewart, who independently discovered the virus in the same year. Finally, in 1961, Gross published the first book wholly devoted to tumour viruses.

Twenty years ago Gross's Oncogenic Viruses was the only comprehensive general text available. As such, the book was invaluable. A second enlarged edition was published in 1970 which included much new material, though it omitted discussion of some of the most interesting in vitro experimentation on oncogenic viruses and cell transformation established during the 1960s. Now Gross has produced a third edition, expanded to two volumes, and including some new chapters on oncogenic viruses of fish, "slow virus diseases" and iatrogenic transmission of human cancer.

I looked forward to reading this new edition in the hope of seeing the recent strides made in experimental oncology placed in perspective by the man who discovered two of the most intensively studied tumour viruses. I was deeply disappointed. Whilst Gross writes in his introduction that "all chapters . . . have been brought up-todate in order to include the most important observations which have become available since the previous edition was prepared", this is a travesty of what follows. For instance, there is not a single citation of David Baltimore's work, either on reverse transcriptase (which is never mentioned), or on Abelson leukaemia virus (this important virus and its associated neoplasms are dismissed in a single paragraph).

Gross excludes any discussion of viral replication and genetics. This could be explained by his remark that "molecular biology is not discussed in this book". But while the author wisely did not aim to write a detailed molecular treatise, no modern text can afford to ignore the results of molecular biology in changing our conception of tumour virus biology, and indeed of cancer as a whole. It is difficult to see how any author can claim to present insights into viral oncogenesis without at least a nodding reference to "early" functions of papovaviruses or to retrovirus oncogenes.

By eschewing all data on viral and host genetics, whether obtained by classical or molecular methods, much of value in the detailed descriptions of early virus isolates is diminished. Such important topics as viral transmission, defectiveness, and host permissiveness and resistance are discussed in terms of concepts that were already outdated at the time of the second edition 13 years ago. For example Gross himself coined the terms "vertical" and "horizontal" transmission for tumour viruses in 1944, and the existence of hereditary infections is described at length in many chapters. Yet the crucial distinction between congenital infection and the Mendelian inheritance of integrated proviruses is not made until the final chapter, almost as a footnote. Classical papers, such as those by Payne and Chubb (J. Gen. Virol. 3, 379; 1968) on the Mendelian inheritance of viral antigens in chickens and Bentvelzen and Daams (J. Natl Cancer Inst. 43, 1025; 1969) on the chromosomal transmission of mammary tumour virus genomes in GR mice are not cited, let alone the wide body of knowledge on endogenous viral elements accrued in the 1970 s which clarified the whole subject of retrovirus latency and activation. Gross devotes five chapters to murine leukaemogenesis without once mentioning xenotropic or recombinant viruses.

The considerable progress in the study of human oncogenic viruses since the last edition receives erratic treatment. With the burgeoning interest in human papilloma viruses and the isolation of new strains associated with particular neoplasms, it is astonishing to find the most recent reference dates from 1965. Hepatitis B viruses of humans and animals are summarized in one-and-a-half pages, and human T-cell leukaemia virus in one page plus an electron micrograpti. There is, however, a whole chapter on Fpstein-Barr virus, and a useful new char :er on "Inadvertent and Experimental Transmission of Human Cancer"'.

As an historical survey of viral oncology up to 1965 , Oncogenic Viruses is unparalleled. But no reader or librarian should suppose that this new edition gives a contemporary account of viral oncology. As with Darwin's Origin of Species, I shall treasure the earlier editions, and regret that Gross has devoted much effort on a third edition which should not have been published.

Robin Weiss is Director of the Institute of Cancer Research, London. 